\author{
International Journal of Education, \\ Psychology and Counselling (IJEPC) \\ Journal Website: http://ijepc.com/ \\ eISSN: 0128-164X
}

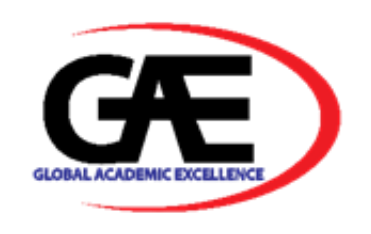

\title{
FAMILY IN TALENT AND CREATIVITY DEVELOPMENT
}

\author{
Ahmad Abd Mustafa Smadi ${ }^{*}$, Bsaer Ahmad Mustafa al-Qudah², Najihah Abd Wahid ${ }^{3}$ \\ 1 Universiti Sultan Zainal Abidin, UNISZA \\ Email: Ahamad.abedsmadi@gmail.com \\ 2 Email: Bsaerahmad@gmail.com \\ 3 Faculty of Islamic Contemporary Studies, Universiti Sultan Zainal Abidin, UNISZA \\ Email: anajihah@unisza.edu.my \\ * Corresponding Author
}

\section{Article Info:}

\section{Article history:}

Received date: 06.01.2020

Revised date: 18.05 .2020

Accepted date: 14.06 .2020

Published date: 15.06 .2020

\section{To cite this document:}

Smadi, A. A. M., Al-Qudah, B. A. M., \& Abd Wahid, N. (2020). Family in Talent and Creativity Development. International Journal of Education, Psychology and Counseling, 5 (35), 215-224.

DOI: $10.35631 /$ IJEPC.5350019.

\begin{abstract}
:
Talent and creativity development require extraordinary counselling from the members of the family, and as such, it is necessary to highlight the crucial role of family counselling towards developing talent and creativity. The article aims to examine the contributory role of the family in talent and creativity growth. The study shall serve as a reference for families to eliminate challenges growing with talent and creativity maturation. If the family has no awareness of how to deal with their gifted son, it may cause psychological stress and academic problems, thus undoubtedly affect the child's talent. Hence the importance of this study is to demonstrate the role of family counselling in developing the talent and creativity of the gifted child by providing support and awareness to the family on how to deal with this talent to preserve and develop this talent because the gifted individuals are the basic building blocks in the progress and development of societies. Therefore, the article attempts to analyse the talent and creativity of gifted children, and counselling of gifted family. The article includes a quick overview of talent origins, components and techniques, the role of the family in talent and creativity development, family factors influencing talent, creativity, gifted children, and family counselling. The study is qualitative descriptive research since the approach is considered suitable for determining the particular role expected from the family towards developing talent and creativity. The approach used in this study is appropriate for pinpointing the responsibilities of families in the process of growing children's talent and creativity.
\end{abstract}

\section{Keywords:}

Talent, Creativity, Counselling, Development 


\section{Introduction}

Despite the importance of family counselling in child upbringing, the family's knowledge and skills regarding children's talent development are still lacking. Limited knowledge about the function of the family in the growth of children's talent may increase the prevalence of unimaginative among children. Ignorance of effective family counselling-steps for talent development may amount to dull and boring moments for the children.

Family counselling can guide families to control the development and maturation of their children's talent. These guidelines and instructions can proffer useful solutions for the entire members of the family while handling the challenges of talent development. Family counselling has the capacity of controlling talent growth and enhancing creativity. It plays a role in the process of behavioural change including interest and adoption, thus increases family's knowledge, attitude and skills to control children's talent development. Hence, the purpose of the study is to explore the role of family counselling in developing talent and creativity.

\section{Literature Review}

Neuhaus \& Neubern (2013) stated that family factors, such as safety and non-fear, are influenced by the factors influencing creativity development, while family factors such as tolerance and fostering intimacy influences raising children and encouraging them to innovate. Innovation and confidence self-motivation and the desire to experience, adventure and independence have a great impact on the development of talent by encouraging the talented factor in creativity development among children, by promoting self-confidence, desired experience, adventure, and autonomy. All these have the greatest impact on talent development by encouraging the talented worker to develop creativity among their children. School management is also essential by saving time and resources needed to develop gifted talent and stimulate it towards creativity.

As for the family status, Jang \& Kim, Park (2017) identified the most important factors influencing the development of creativity, including family factors, where they include the social and economic level of the family, and the family's method of raising and dealing with children. Al-Ma'aytah and Al-Bawaz (2014) also mentioned the factors that affect creativity development in the educational literature, namely: culture, family, parents' nature, commitment, maturity, education, antiquities, mental health, identity formulation, environment and individual living systems, acceptance and encouragement, especially in the early childhood, individual's internal motivation and protection from external impediments and knowledge.

As for the socioeconomic level, several studies, such as the study of Isa (2016) showed that the family socio-economic level affects talent development. This is in the case of the father's educational status, father's occupation, monthly income, parents' family status, number of family members, presence in the house, number of rooms in the house, and type of housing.

In terms of family upbringing, studies such as Zahran, Ben Ghani and Zahrani-Al (2014) have confirmed that the democratization of families in raising their children contributes to their talent development, while the use of dictatorship and additional supervision kill the talent. There is need to highlight the role of the family in developing children's talent, as well as family factors that help in achieving this by exploring the importance of counselling talented 
families and identifying the impact of counselling on the talent of these individuals. Furthermore, the study deems it necessary to mention the most important techniques that can be taken into account when counselling talented families.

\section{Talented Individuals}

Gottfried et al. (1994) asserted that the higher socioeconomic status consistently discovered for the families of talented children compared to non-talented children is more likely attributed to the higher educational level of both parents. Albert (1980, 1994)'s follow-up study with talented boys and their families showed that fathers influenced their sons' creative potential ability. The study involved 26 families of mathematically and scientifically talented boys (aged 11-14) who participated in the Study of Mathematically Precocious Youth (SMPY) and 25 families of 12-year-old boys with high IQs (150 or above). The results from interviews with both parents from the creativity measures (e.g., the Biographical Inventory of Creativity: BIC and the Wallach-Kogan Test of Creative Potential) revealed that a family's emphasis on the father's involvement in his son's daily and extracurricular activities (e.g., music, sports, languages, reading, etc.) positively influenced the son's (both high-IQ and mathematically gifted groups) performance on the BIC.

Case analyses of eminent people demonstrated the significant roles families, particularly, fathers played in facilitating children's academic and creative talent development. Piirto's (1998) biographical studies of creative people exemplified how fathers contributed to the development of giftedness and talents of many prominent people. An emphasis on reading in the family was one of the prominent atmospheres found for many creative writers (e.g., Jane Austen, Virginia Woolf, the Bronte“ family, Tennessee Williams, Stephen Crane), and some of them such as Thomas Wolfe and George Eliot attributed their success specifically to their stimulating and nurturing fathers. Among creative scientists, parents were the intellectual stimulators who would discuss issues of science and math with their children. For creative artists, such as Wolfgang Amadeus Mozart, Igor Stravinsky and Pablo Picasso, parents served as their initial teachers in developing their musical or artistic talents in early childhood (Gardner 1993).

Goertzel and Hansen (2004) analyzed the lives of 400 distinguished individuals. They were identified as "eminent" by having at least two biographies of their own and being recognized as making positive contributions to future generations in various fields (e.g., literature, art, music, sports, science, math, politics, acting, etc.). The authors found that over $90 \%$ of the families of these eminent people showed a passion for learning and achievement, and parents, either one parent or both, were intellectually stimulating, curious, supportive, opinionated and hardworking. One noticeable finding was that the majority of them had troubling fathers but stronger, dominating mothers, although their home environments were full of respect for learning and achievement. For example, half of the fathers were found to be troublesome, and they had experienced frustrations and failures, and many of them were alcoholics as well. Goertzel and Hansen concluded that these failure-prone fathers enabled their children to be released from the fear of innovation, a contributing factor to being creative in adulthood. Moreover, many of these creative people identified themselves with their fathers in terms of being experimental and taking risks in the development of their giftedness and talents even if they were not always efficient in doing so. 
Albert's (1994) study of 50 families of high IQ versus mathematically gifted boys showed a significant relationship in personality profiles between fathers and sons. Students with 150 or above IQ scores on the Stanford Binet test were identified as having a high-IQ, while students who participated in the SMPY (ranked within the top 1 percentile based on their SAT math scores) were placed into a gifted math/science group. Findings included that on the California Psychological Inventory (CPI), both parents of the high-IQ boys showed similar profiles to each other, while those of the gifted math/science boys were different in that fathers obtained higher scores than mothers in several subscales of the CPI, such as dominance, self-acceptance, good impression, intellectual efficiency, achievement through conformance and well-being, that tap into a comprehensive array of personality factors.

\section{Talent and Creativity Development}

Ajilat (2017) defined talent as a privilege possesses by an individual, which means first natural preparation, unusual inherent potential energy in one or more areas of human preparedness that are socially appreciated in a given place and time, and which can qualify an individual with a distinct future in one of the fields of activity to achieve the levels of human performance associated with this preparedness if it has the necessary personalities, motivational factors and proper environmental conditions. Through this definition, it is evident that talent is linked with an individual's preparation and characteristic by showing its distinctiveness and difference from other members of society, which are positive attributes desirable to the communities.

Al-Zu'ayb (2015) pointed out that the most important justification for gifted attention is that the normal educational climate is not suitable for them and that they need special programs to achieve the balanced growth of their personality. This is also confirmed by Abdul Aziz and AlKawafah (2015). The percentage of talented people who make up 3\% on the natural distribution curve, and the existence of different characteristic needs of other community members, having problems with regular programs, as well as with the environment they are dealing with, including their families. All of these prompted students to conduct studies on these groups, as well as studies on all the mix communities, including their families.

The family that an individual, elderly, adult and a young man need to raise and care for, will have the greatest impact on the formation of his personality and the direction of his behaviour. It is the talented family that cares primarily for the talented regardless of their talent. Ajilat (2017) emphasized that family plays a role that is considered as the first social institution that embraces the talented, and it is influenced by all the customs and traditions that lead to the dyeing of social behaviour.

There is a constant principle that the process of talent development lacks hierarchical integration of invariant sequences and stages when compared with human development (Feldman 1982). The concept of talent is synonymous to giftedness (e.g., Feldhusen 1992) or intelligence (e.g., Gardner 1983, 1999) or it is a constituent of giftedness (e.g., Feldhusen 1986) or other relevant constructs such as creativity (e.g., Csikszentmihalyi et al. 1997; Csikszentmihalyi 1996).

Gagne's $(1995,2003)$ differentiated model of giftedness and talent (DMGT). In the DMGT, talent is defined as the mastery of systematically developed abilities, skills, and knowledge in a particular field of human activities, while giftedness (or gifts) is described as the possession and use of untrained, spontaneously represented natural abilities or aptitudes in a certain ability 
domain. Gagne' $(1995,2003)$ viewed talent as a developmental construct, an index of achievement or performance preceded by systematic training and practice. On the other hand, the concept of giftedness is viewed as necessary, but not a sufficient condition to the emergence of talent. Therefore, the DMGT posits that all talented children are gifted, but not all gifted children grow up to be talented unless they receive the necessary support from the family in the process of talent development.

Treffinger and Feldhusen (1996) asserted that talent is growing, nurturing and developing rather than fixed and static, and thus, it requires appropriate counselling from the members of the family to be fulfilled. Researchers supported the developmental perspective of talent and recommended that the process of talent development involves the coordination of factors that leads to faster, advanced and profound development. One factor may play a greater role than others based on children's ages and talent areas, but the co-emergence of multiple aspects of human characteristics and social environments, such as interpersonal or intrapersonal characteristics, societal forces, and chance or luck (Gagne' 1995, 2003). Feldman (1982) called the concurrent emergence of those factors "coincidence" and listed several factors such as culture, the timing of talent discovery, tradition, history, institution, mentors and instruction as essential to fulfilling talents. Feldman claimed that coordination of various forces that involve family, peers, teachers, and mentors as well as historical, cultural, social, and individual characteristics enable children to develop their giftedness and reach an optimal level of talent development.

The process of talent development cannot be fully explained in the Piagetian universal and sequential stage model of human development (Feldman 1982). It is idiosyncratic, dynamic and involves a wide array of components comprising intellectual, affective, social, and chance forces in every period of human development. Talent requires continuous support, arduous work and contributions from multiple parties to emerge as a developed performance and expertise in a particular field of human activities, and specifically, families are the first important agents who recognize children's potential abilities and channel them into their special talent areas.

Child attention during the early stages of development is important and enthusiastic in his life, especially in the early years of childhood, where he begins to discover the components and use of language, accompanied by curiosity and identification of objects and discovery of seeing their formations and touching their surfaces, and seeking their voices, and recognizing their taste and smell, which is good to vary from one another. Torrance (n. d.) pointed out that the first five years of a child's life are critical to the development of creative abilities, as they show a wide imagination through their games and stories and stressed the importance of using various appropriate educational methods to help children develop their creativity. When a family has a strong influence on an individual's personality, the interactions that occur between him and his family's environment have a major role in his or her personality, and if the interactions are healthy, they will generate different problems for both the gifted and the family.

Peter (2018) identified family problems as a result of erroneous family interactions that lack guidance. For the family to avoid these problems and consequences for the gifted talent, it is essential to propose a frame of guidance attempting to modify relationships within the family. The need to guide gifted families is centred around several things, initiated by (Abu Asaad, 2018) with the help of parents to know the proper dealings with the talented, by alerting the 
characteristics of the talented and how to develop and help the talented on how each party deals with the other. To fairly deal between the talented and parents, this kind of guidance help parents in understanding the gift of their talented son, and it also helps them not to link talent with high marks, which in turn reduces the pressure on the talented, and makes him able to manage himself on the collection side, as it is noticeable that the talented pressure to achieve high marks, affects his talent, and generates psychological and study problems.

From the above, it can be noted that if the family is aware of the needs and characteristics of the talented child, it will reflect on the family's comfort towards the gifted son, by not linking talent to achievement at the level of achievement. The gifted need to be supported within his family, as it relieves psychological stresses that may be the source of the family's safety, which, in turn, makes it possible for the family to be gifted, and which also enable the gifted to embark strongly in the school and community.

A family that has an awareness of how to deal with its gifted son does not limit its protection on problems and psychological stress, but also helps the gifted to develop his talent. This is in many ways similar, as Suleiman (2013, pp. 1-2) stated, that the family develops a kind of intimate relationship based on love and mutual respect among child, parents and family members, to avoid the use of intimidation methods, and the removal of the child from the areas of fear, especially the fear of making mistakes and leave the opportunity for the child to make multiple attempts, and urge the child to use imagination and transcend the familiar sensible objects, move ink between reality and imagination, and try to form assumptions and fictional formations, and use humor and playfulness, make the child feel relaxed, realistic with surrounding obligations, help them with the ambiguities associated with fictitious situations, educate the child on the flexibility and non-rigidity of thinking, leave the freedom to choose and make decisions, try to instill new solutions, and not rely on preconceived solutions that the child has developed in advance, which the child has prepared to use and as such, the child does not bother to think and look for other ways and methods.

All these means and aspects that can be provided within the family atmosphere to reflect strongly on the gifted talent, emphasizes the factors affecting the development of talent by the gifted family, and many studies and researchers have identified the most important factors affecting the development of creativity among students and individuals.

\section{Family in Talent and Creativity Development}

In talent development, one of the major roles of the family is to adopt and enact special values and supportive actions essential to their children (Olszewski-Kubilius 2008). Families also structure and direct children to particular talent areas (Olszewski et al. 1987; OlszewskiKubilius 2008). They expose their children to various cultural experiences; provide access to educational programs, materials and private lessons; and engage themselves in their children's educational activities so that they can identify their children's unique abilities and explore new opportunities that facilitate their talent development (Olszewski-Kubilius 2008; OlszewskiKubilius and Lee 2004).

Bloom's (1985) landmark study of 120 talented youths proved the important influences of family support and involvement in the process of talent development. Using interviews with over 100 talented people in the areas of music, art, athletics, math, and science, the authors discovered that children's talents were formed and developed according to the three phases of 
learning, consisting of early years (roughly before age 10), middle years (around ages 10-14) and later years (after around age 14), using affiliations with significant people. Parents were found particularly pivotal for talent development in the early to middle years of the learning stage since they did not only recognized children's special talents but also introduced and took the initiative to direct children to their first talent areas. The study demonstrated that parents manoeuvred the process of children's talent development and that their involvement and support were more influential than children's gifts and talents before the age of 10 .

\section{Discussion}

Academic benefits for children resulting from families' involvement were found in terms of improving problem-solving skills such as mathematical or language skills (Crockett et al. 1993), vocabulary knowledge (Biller 1993) and cognitive functioning (Kelly 2000); facilitating creative potential, special talents (Goertzel and Hansen 2004) or better performance (higher GPAs) in school (Shinn 1978); forming the positive perceptions of academic self-efficacy and schools (Flouri et al. 2002); and enhancing motivation for learning, achievement (Blanchard and Biller 1971) and successful educational, economic (Harris et al. 1998) or professional attainment (Montgomery and Benbow 1992). For effective talents, various issues regarding the development of gender role identity (Biller 1970); psychological good adjustment (Grossmann et al. 2002); healthy personality characteristics such as independence, autonomy, initiative, persistence, higher self-esteem and confidence (Goertzel and Hansen 2004; The National Institute of Child Health and Human Development Early Child Care Research Network 2008); positive mood and happiness (Amato 1994); advanced morality (Hoffman 1971); less behavioural problems in and outside of school (Coley 2003); and close friendships (O'Neil and Parke 2000) were linked with paternal involvement.

For children of mixed ability, previous research overwhelmingly supported that fathers had a greater impact on the cognitive, intellectual development of boys than girls (e.g., Blanchard and Biller 1971; National Institute of Child Health and Human Development Early Child Care Research Network 2008). Studies involving talented students found differences between the families of academically talented children versus their non-talented counterparts in their educational, socioeconomic and occupational profiles (Goertzel and Hansen 2004) or personality characteristics (Albert 1994), mostly favouring the former. Siegal's (1987) review also revealed that families (father and mother) treated and behaved differently toward sons and daughters (e.g., stricter, firmer, more physical play and exploration with sons than daughters) and even more differentiations were found among fathers when mothers were not present with children.

\section{Conclusion}

In conclusion, the talk in this area is an unending discussion, and has many ramifications that need to be elaborated and prolonged. Talent is an investment for any country and the entire world. In this regard, practical programs need to be developed to activate the role of the family in developing talented children.

The most important techniques for counselling talented families is by presenting information to the talented families through lecture, dialogue, discussion, technical reformulation and family embodiment technique. The lecture aims at presenting information to talented families. Dialogue, which is a group discussion aims to strengthen communication between the mentor and the talented family with encouraging dialogue and discussion. This also includes technical 
reformulation, which is the restructuring of attitudes facing the family member. It aims to redefine irrational ideas and show a new vision towards the talented. Aside from that, the family embodiment technique identifies the nature of the family format, that aims to raise awareness among family members in the way they communicate, including communication, positive response and other things that can be set up for continuous communication with the talented family, and by guiding them to the best ways of dealing with their talented child, to achieve the best benefit.

Hence, the role of the family in talent and creativity development is positive and promising. Though the foremost role of fathers is still to provide financial support for family members and mothers remain the primary figures identifying children's special talents. Fathers are the significant sources of motivation and support for children's talent development and professional role models for their talented children.

\section{References}

A Neber, H., \& Neuhaus, B. J. (2013). Creativity and Problem-Based Learning Excellence. Singapore: Springe Neglected Relation. Creativity, Talent and Personality Influencing.

Abu Asaad, Ahmad Abdul Latif. (2018). Guidance for the gifted and talented. Oman: Dar AlMisseriya for Publishing, Distribution and Printing.

Al - Zahrani, M., Bin Ghani, M. \& Che, A. (2014). A comparative Study between the by Methods of Democracy, Dictatorship, Idleness and Excessive Protection Used Jeddah, Saudi Arabia. Parents from the Viewpoint of the Talented Students in the City of Language in India, 14 (11): 68 - 94.

Al-Ajeelat, Abdel Baqi. (2016). The role of the Algerian family in caring for gifted children who excel in modeling, a field study on a sample of students attending the baccalaureate in the governorate of Sétif, unpublished doctoral thesis, University of Mémiline Tannery of Setif 2, Setif - Algeria.

Albert, R. S. (1980). Exceptionally gifted boys and their parents. Gifted Child Quarterly, 24(4), 174-179.

Albert, R. S. (1994). The contribution of early family history to the achievement of eminence. In N. Colangelo, S. Assouline, \& D. L. Ambroson (Eds.), Talent development: Proceedings from the 1993 Henry B. and Jocelyn Wallace national research symposium on talent development (pp. 311-360). Dayton, OH: Ohio Psychology Press.

Al-Ma'aytah, Khalil Abdul-Rahman \& Bawaliz, Mohammed Abdul-Salam (2014). Talent and excellence. Amman: Dar Al Fikr Publishers and Distributors.

Al-Sorour, Nadia Hale. 2013. The behavioral characteristics of creative students in ordinary classes from the point of view of teachers in a Jordanian sample. Inter studies, 40, 649664.

Al-Zu'ayb, Ahmad Mohammed. (2015). Talent, excellence and creativity: methods of detection, guidance and care. Amman: Dar Al Fikr Publishers and Distributors.

Amato, P. R. (1994). Father-child relations, mother-child relations, and offspring psychological well-being in early adulthood. Journal of Marriage and the Family, 56, 1031-1042.

Asi, K. (2016). The Level of Shyness among Talented Students Economic Level of the Family in Riyadh. Practice, 7 (15): 48 -53. Journal of Education and (PBL):

Biller, H. B. (1993). Fathers and families: Paternal factors in child development. Westport, CT: Auburn House.

Blanchard, R. W., \& Biller, H. B. (1971). Father availability and academic performance among third-grade boys. Developmental Psychology, 4(3), 301-305. 
Bloom, B. S. (1985). Generalizations about talent development. In B. S. Bloom (Ed.), Developing talent in young people (pp. 507-549). NY: Ballantine Books.

Boutros, Hafez Boutros. (2018). Guidance for people with special needs and their families. Oman: Dar Al-Misseriya for Publishing, Distribution and Printing.

Coley, R. L. (2003). Daughter-father relationships and adolescent psychosocial functioning in low-income African American families. Journal of Marriage and Family, 65, 867-875.

Creative Park, J., Kim M., \& Jang, S. (2017). Analysis of Factors Studies, 10 (5)167 - 180 of Elementary School Students. International Education.

Crockett, L. J., Eggebeen, D. J., \& Hawkins, A. J. (1993). Fathers' presence and young children's behavioral and cognitive adjustment. Journal of Family Issues, 14, 355-377.

Csikszentmihalyi, M. (1996). Creativity. New York: Harper Collins.

Csikszentmihalyi, M., Rathunde, K., \& Whalen, S. (1997). Talented teenagers: The roots of success and failure. Cambridge: Cambridge University Press.

Feldhusen, J. F. (1986). A conception of giftedness. In R. J. Sternberg \& J. E. Davidson (Eds.), Conceptions of giftedness (pp. 112-127). NY: Cambridge University Press.

Feldhusen, J. F. (1992). TIDE: Talent identification and development in education. Sarasota, FL: Center for Creative Learning.

Feldman, D. H. (1982). A developmental framework for research with gifted children. In D. H. Feldman (Ed.), New directions for child development: Developmental approaches to giftedness and creativity (pp. 31-45). San Francisco: Jossey-Bass.

Flouri, E., Buchanan, A., \& Bream, V. (2002). Adolescents' perceptions of their fathers' involvement: Significance to school attitudes. Psychology in the Schools, 39(5), 575582.

Gagne', F. (1995). From giftedness to talent: A developmental model and its impact on the language of the field. Roeper Review, 18(2), 103-111.

Gagne', F. (2003). Transforming gifts into talents: The DMGT as a developmental theory. In N. Colangelo \& G. A. Davis (Eds.), Handbook of gifted education (3rd ed., pp. 60-74). Boston, MA: Allyn \& Bacon.

Gardner, H. (1993). Creating minds: An anatomy of creativity seen through the lives of Freud, Einstein, Picasso, Stravinsky, Eliot, Graham, and Gandhi. New York: Basic Books.

Goertzel, T. G., \& Hansen, A. M. W. (2004). Cradles of eminence: Childhoods of more than 700 famous men and women (2nd ed.). Scottsdale. AZ: Great Potential Press.

Gottfried, A. W., Gottfried, A. E., Bathurst, K., \& Guerin, D. W. (1994). Gifted IQ early: Developmental aspects: The Fullerton longitudinal study. New York: Plenum Press.

Grossmann, K., Grossmann, K. E., Fremmer-Bombik, E., Kindler, H., Scheuerer-Englisch, H., \& Zimmermann, P. (2002). The uniqueness of the child-father attachment relationship: Fathers' sensitive and challenging play as a pivotal variable in a 16-year longitudinal study. Social Development, 11(3), 307-331.

Harris, K. M., Furstenberg, J. F. F., \& Marmer, J. K. (1998). Paternal involvement with adolescents in intact families: The influence of fathers over the life course. Demography, 35(2), 201-216.

Hoffman, M. L. (1971). Father absence and conscience development. Developmental Psychology, 4(3), 400-406.

Jarwan, Fathi (2013). Talent, excellence and creativity. Damascus: Dar al-Fikr.

Kawafiha, Taysir Mufleh and Abdul Aziz, Omar Fawaz. (2015) .Introduction in Special Education. Oman: Dar Al-Misseriya for Publishing, Distribution and Printing. 
Kelly, J. B. (2000). Children's adjustment in conflicted marriage and divorce: A decade review of research. Journal of the American Academy of Child \& Adolescent Psychiatry, 39(8), 963-973.

Mohammed, Abdul Sabour Mansour. (2013). Talent, excellence and innovation. Riyadh: Dar Al-Zahraa for Publishing and Distribution.

Montgomery, J. L., \& Benbow, C. P. (1992). Factors that influence the career aspirations of mathematically precocious females. In N. Colangelo, S. G. Assouline, \& D. L. E. Ambroson, Talent Development (Eds.), Talent development: Proceedings from the 1991 Henry B. and Jocelyn Wallace national research symposium on talent development (pp. 384-385). Unionville, NY: Trillium Press.

National Institute of Child Health and Human Development Early Child Care Research Network. (2008). Mothers' and fathers' support for child autonomy and early school achievement. Developmental Psychology, 44(4), 895-907.

O’Neil, R., \& Parke, R. D. (2000). Family-peer relationships: The role of emotion regulation, cognitive understanding, and attentional processes as mediating processes. In K. A. Kerns (Ed.), Family and peers: Linking two social worlds (pp. 195-225). Westport, CT: Greenwood Publishing Group.

Olszewski, P., Kulieke, M., \& Buescher, T. (1987). The influence of the family environment on the development of talent: A literature review. Journal for the Education of the Gifted, 11(1), 6-28. Olszewski-Kubilius, P. (2008). The role of the family in talent development. In S. I. Pfeiffer (Ed.), Handbook of giftedness in children: Psychoeducational theory, research, and best practices (pp. 53-70). New York: Springer.

Olszewski-Kubilius, P., \& Lee, S.-Y. (2004). Parent perceptions of the effects of the Saturday Enrichment Program on gifted students' talent development. Roeper Review, 26(3), 156-165.

Piirto, J. (1998). Understanding those who create (2nd ed.). Scottsdale, AZ: Gifted Psychology Press.

Sa'adat, Jawdat Ahmad. (2014). School curriculum for the gifted and distinguished. Amman: Dar Al Shorouk for Publishing \& Distribution.

Shinn, M. (1978). Father absence and children's cognitive development. Psychological Bulletin, 85(2), 295-324.

Siegal, M. (1987). Are sons and daughters treated more differently by fathers than by mothers? Developmental Review, 7, 183-209.

Sulaiman, Nora. (2013). (Retrieved from source on 2/5/2018 https://fac.ksu.edu.sa/sites/default/files/dwr_lsr_fy_tnmy_lbd_ld_ltfl.doc The Holy Quran

Treffinger, D. J., \& Feldhusen, J. F. (1996). Talent recognition and development: Successor to gifted education. Journal for the Education of the Gifted, 19(2), 181-193. 